Federico Favali

Independent Researcher

Lucca, Italy
UDC 78.071.1:929 Thorvaldsdottir A.

doi: $10.5937 / \mathrm{ZbAkU} 2008112 \mathrm{~F}$

Original scientific paper

\title{
Entropic Dynamics and Rhizomatic Archetypes in Aeriality by Anna Thorvaldsdottir
}

\begin{abstract}
Icelandic composer Anna Thorvaldsdottir is part of the new generation of composers who have already gained international exposure. As she herself explained, her compositions are born from nature: from her long walks and from the observation of the dynamics, colors and sounds of nature itself. The piece for orchestra Aeriality (2011) is a good example of this poetics. This paper intends to analyze this composition in detail and talk about the author's poetics. Following my idea of an „open“ musicology, that is related to other forms of knowledge and not a description of the score following a specific analytical method, first of all possible relationships between compositional structures that can be described in a quantitative way will be investigated. Particular importance will be given to the concept of entropy by translating this concept into musical terms. Specifically, it will be shown how the displacement of sound masses in the orchestra determines an increase or decrease in entropy. Then the work will be analyzed according to the philosophy and thought of Gilles Deleuze. In particular, taking into account a main concept of his thought which is the rhizome. In concrete terms, it will be shown how the score contains rhizome archetypes and therefore it is possible to read it from this point of view. The intent therefore is to combine the work of this composer with an innovative approach.
\end{abstract}

Keywords: Aeriality, analysis, Thorvaldsdottir, entropy, Deleuze.

In this everyday world, that looks so much like to the book of One Thousand and One Nights, there is not a single gesture that can't have the risk to be a magic operation, there's not a single fact that can't be the first of an endless series. ${ }^{1}$ J. L. Borges

$1{ }^{1}$ Borges, La cifra (1981), in Borges. Tutte le opere II. Translation of the author. 
It is well known that poetry was the first native literary tradition to emerge in Iceland. Most of the works originated in Scandinavia before the colonization of the island. However, it is only from the twelfth century that compositions were written. ${ }^{2}$ The poetic texts of that period were divided into two categories: Eddic poetry (similar to prose in free metrics) and Skaldic poetry (which used complex verses and a welldefined vocabulary). Over time, Icelandic poetic tradition has remained very much alive. In fact, many different poets have written in later centuries. They are still writing today, bewitched by the beauty of the nature of this island, which exerts a kind of magic on their sensibilities.

Other artists have also been influenced by the natural beauty of the island. In terms of music, some notable composers include Sveinbjörn Sveinbjörnson (18471927), Emil Thoroddsen (1898-1944), and Jón Leifs (1899-1968).

Anna Thorvaldsdottir's orchestral piece Aeriality (2011) is part of this tradition. The composition is characterized by the fusion of large sound textures with various forms of lyrical material. ${ }^{3}$ The title refers to slipping in the air, with little or nothing to cling to. The music communicates a feeling of freedom with a lack of friction, while at the same time illustrating the discomfort generated by the same circumstance. The title Aeriality originates from various aspects of the word ,air". It is also a play on words that combines the words ,,aerial“" and ,reality“. This is to suggest two different worlds: ,reality“ as the ground and ,aerial“" as the sky or untouchable. On the composer's website, she writes:

,[...] the composition is on the border between symphonic music and sound art. Parts of the piece are made up of great masses of sound that move, slide on each other, and vanish. The sense of the individual instruments is somewhat blurred and the orchestra becomes a single moving body, although sometimes it forms layers of streaming materials that flow between different instrumental groups. These chromatic layers of materials are extended by the use of quarter tones to generate large sound textures. ${ }^{\text {“4 }}$

2 Although there is no absolute certainty, it seems that Iceland was initially inhabited by Irish anchorite monks, called Papar, who-following the example of St. Brandan of Clonfert-undertook dangerous journeys to test their faith. The monks likely interpreted the migrations of birds as proof of the presence of a land rather than the ocean: a place where men could live. This thought was reinforced by the relative proximity of the Faroe Islands $(450 \mathrm{~km})$. They were visited by Irish hermits already in the sixth century. In fact, as early as the ninth century, Irish monks were able to reach Iceland. Some of them had also spent considerable time there.

$3 \mathrm{Cf}$. http://www.annathorvalds.com/aeriality. Anna Thorvaldsdottir is one of the most interesting voices of a new generation of composers. She writes music characterized by nuances of sound and lyrical material. Her pieces are inspired by nature and its many qualities. Her debut album, Rhizóma, was released in October 2011. Aeriality was written for the Iceland Symphony Orchestra and it is about thirteen minutes in duration, and was premiered at the Reykjavik Harpa Concert Hall and Conference Center by the Iceland Symphony Orchestra on November $24^{\text {th }}$, 2011, conducted by Ilan Volkov. Aeriality was nominated „Composition of the Year" at the Icelandic Music Awards 2012. For more information about the piece cf. http://www.annathorvalds.com/aeriality. It is possible to listen to the piece here: https://www.youtube.com/watch?v=0-iil3YYp5E

4 ibid. 
The listener hears an uninterrupted sound flow which changes morphology, color, and direction, developing without interruption.

To analyze this composition, I chose an analytical approach that can be seen as „open“5.Instead of choosing a particular analytical method, I chose to analyze the work by reading from different points of view. Merging the obtained results will give the final analysis. Thus, the use of multiple methods is itself a method, or rather an analytical approach.

These thoughts can be transferred to the analytical field, keeping in mind that the object of our attention will not only be the performance, i.e., the sounds, but also the score. The aspect of openness lies in the way in which the analyst approaches it. The analyst, according to his own sensitivity and culture, can relate the signs within the score to various areas of knowledge. In this way, aesthetic stimuli can change. Therefore, as a result of this approach, the ways of interpreting the work are different (potentially numerous) and affect the artistic, literary, and scientific spheres. It is in fact possible to utilise scientific concepts and narrative techniques in the analysis to explain certain structures. The score becomes a kind of hypertext that can be approached in different ways. The verse of Paul Verlaine comes to mind:

„La mer, la mer, toujours recommencée!“6

Any work is like a sea that constantly reveals itself and says something about fundamental issues.

Following these arguments, the analysis of Aeriality starts from a scientific point of view, in which the concept of entropy is considered and applied to the composition, describing its entropic dynamics. ${ }^{7}$ A philosophical lens will then be utilised, specifically, how certain aspects of Gilles Deleuze's philosophy_in particular, the rhizome - can say something about the composition. ${ }^{8}$ In this study it has been chosen to focus only on the concept of entropy in physics and of rhizome in philosophy. The aim is to show a new approach of analysis that can be developed and expanded in the future.

5 As the Italian philosopher Umberto Eco explained, the musical work of art can be considered "open" either in the real sense (i.e., when the performer has to manage musical parameters directly) or in the metaphorical sense (i.e., where the performer has to interpret what is written). The approach that I present in this paper has several points in common with the approach that James Webster calls "multivalent analysis.” Cf. William E. Caplin, James Hepokoski, James Webster. Musical Form, Forms \& Formenlehre. 6 Verlaine, Paul, Le cimetiere marin. Translation: „The sea, the sea, always restarted.“

7 The relation between entropy and music has always received a lot of attention. Among recent contributions, one of the most interesting is: Margulis Hellmuth, Elizabeth \& Beatty, Andrew, Musical Style, Psychoaesthetics, and Prospects for Entropy as an Analytic Tool.

8 Among the studies on the influence of Deleuze on musical thought, I started from a number of Perspective of New Music that in 2008 dedicated a volume to Deleuze; in particular: Gallope, Michael, Is there a Deleuzian Musical work?. Then, of course, the book by Prof. Edward Campbell. A recent interesting contribution is: Stover, Chris, Time, Territorialization, and Improvisational Space. 
As previously pointed out, listening has - at the same time - a sense of suspension and of dynamism (generated by an internal movement). It is interesting that, talking about the long duration values present in the score, the author writes in the introductory notes: ,when you see a long held note, think of a fragile flower that you have to carry in your hands, covering a small distance without throwing it or dropping it. "“9 Therefore, in the inherent sound conception, there is the idea of movement that, although in a context of delicacy, brings a small degree of dynamism more or less accentuated (and therefore supplies proportional tension). The fact that this type of sound is built in bands, and also the result is a continuum of sound without interruption, makes it difficult to divide the piece into sections to study the structure. However, as Jonathan Bernard explains in a famous essay ${ }^{10}$, one of the criteria for identifying the sections of a piece is to take into account the diastematic context in which a certain part develops: a change of register may mean a change of section. The timbre is another important aspect of the segmentation. The changes of rhythm and of rhythmic patterns can be an additional factor. Finally, other aspects such as sentence markers, dynamics, texture changes, or pause separations also have the same value. On the other hand, the segmentation does not depend on the degree of evidence shown by these factors. Given these explanations, summarized by the fact that each section must have its own characteristics, Aeriality has been divided into five parts in this study:

Section 1 - bars 1-19; Section 2 - bars 20-52; Section 3 - bars 53- 71; Section 4 - bars 72-91; Section 5 - bars 92-109.

In pieces written in this manner, the fact that the boundaries of the sections are unclear and not defined certainly makes one think of the concept of ,frayed structures“. It is possible to talk about ,frayed structures“ when the connection between two sections does not occur with perfect coincidence of all the constituent levels: that is, when the first section cannot be considered completely closed nor completely open, and the same happens to the second one. ${ }^{11}$ Aeriality utilises ,frayed structures“ for practically all the sections of the piece to underline the desire to create a continuum not only of sound, but also of formal structure. At bar 20 (last bar of Ex. 1), the second section begins, characterized by the wide use of glissandos. It is a small entity in the violas (desk 1 and 2-3 and in the double basses desk 3-4) that then extends to the entire string section.

However, in bar 19 the sound bands of winds and brass continue. At bar 53 in the strings (Ex. 2), the harmonic range changes, and there are sound bands that „bind“ the two sections. The same happens for the next section (bars 73-Ex. 3). In this case, after a long fermata (bar 71), another figure begins. At bar 92, the harmonic range changes again (Ex. 4).

There is no symmetry between the sections: the second section is the longest, and the others have very similar extensions.

9 Cf. http://www.annathorvalds.com/aeriality

10 Bernard, "Space and Symmetry in Bartók", p.192.

11 Cf. Azzaroni, Canone infinito, p. 513-514. 
STUDIJE O MUZIČKOJ UMETNOSTI/STUDIES ON MUSIC

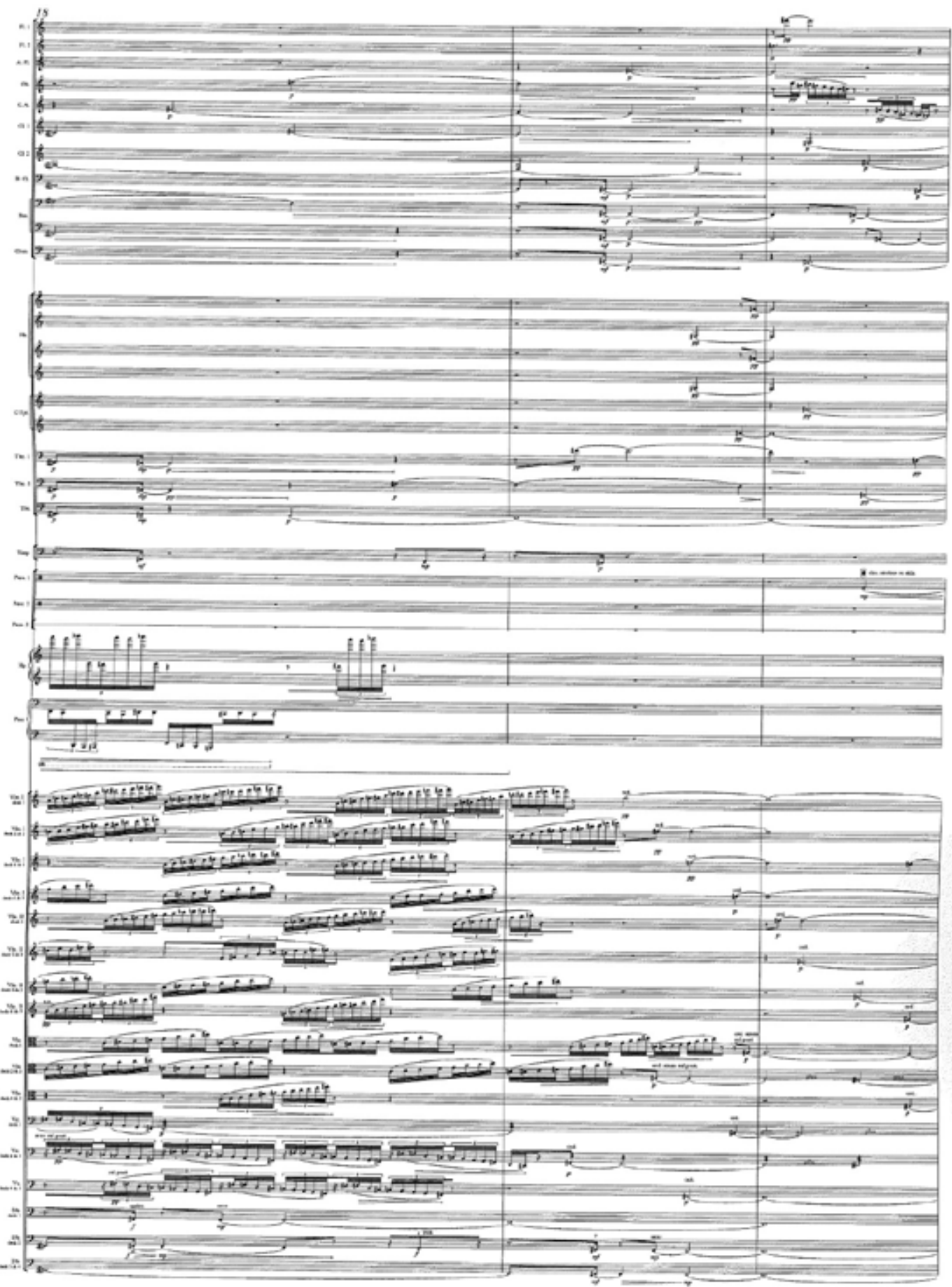

\section{Example 1. Aeriality, bars 18-20}


STUDIJE O MUZIČKOJ UMETNOSTI/STUDIES ON MUSIC

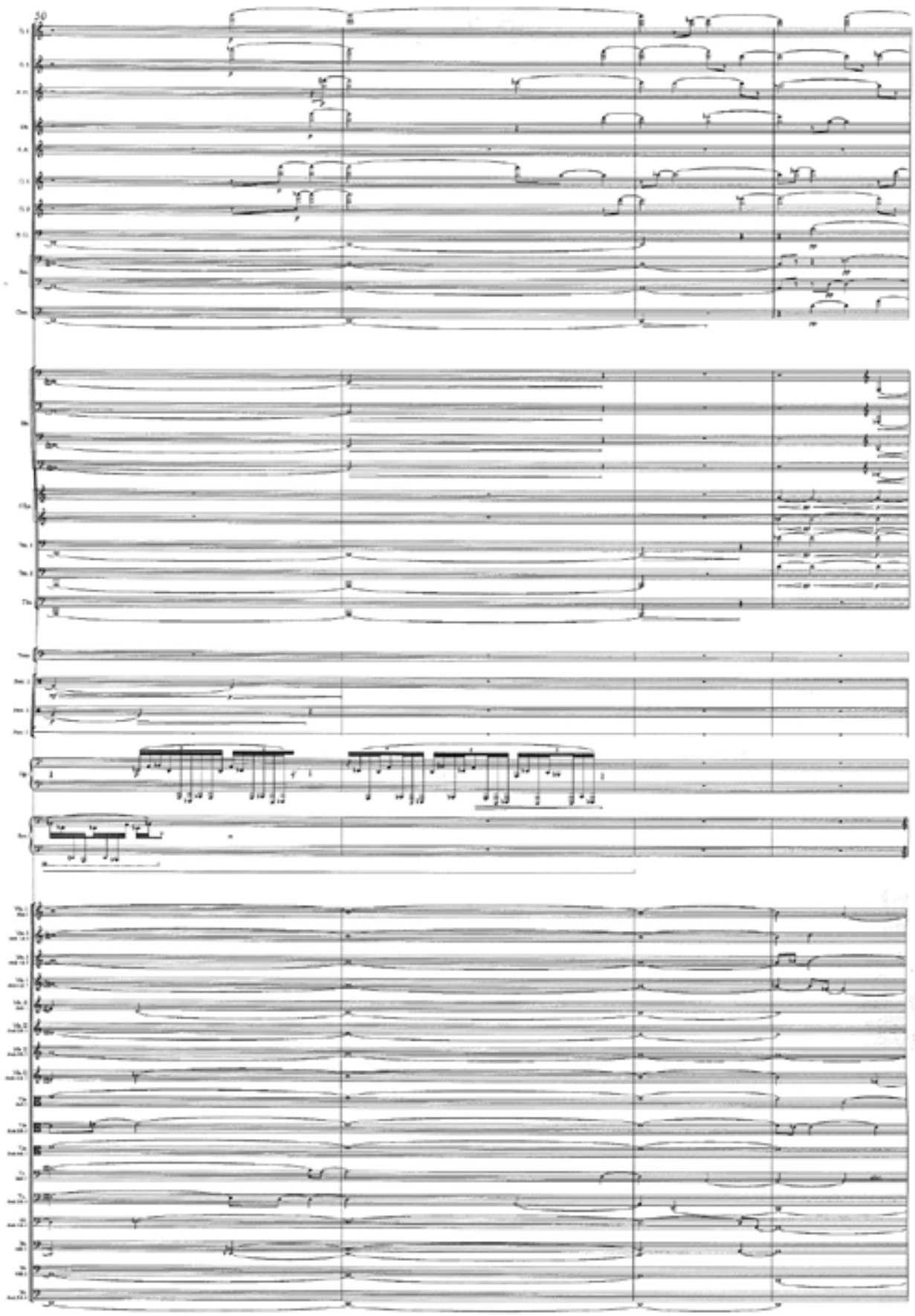

Example 2. Aeriality, bars 50-53 
STUDIJE O MUZIČKOJ UMETNOSTI/STUDIES ON MUSIC

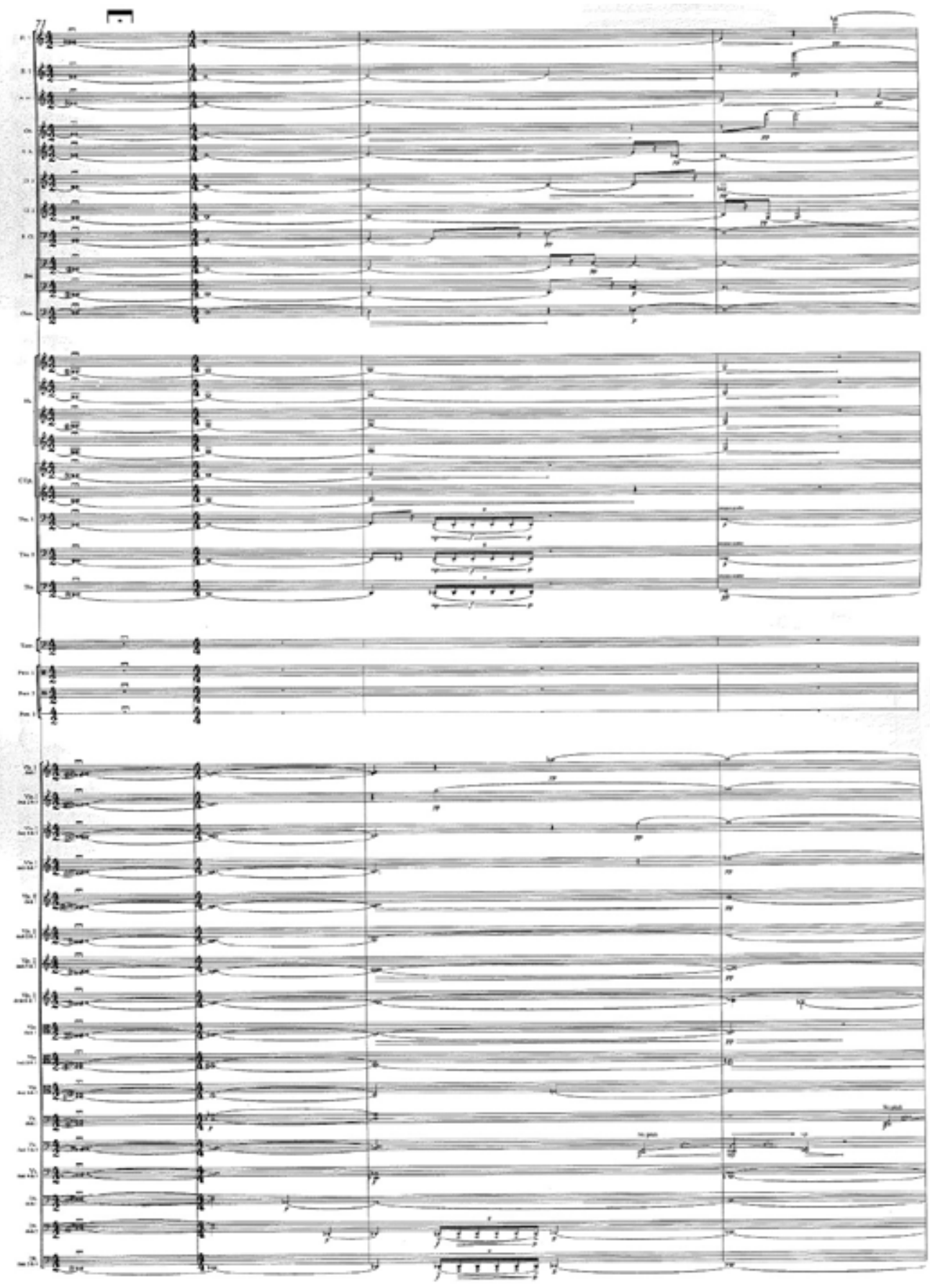

Example 3. Aeriality, bars 71-74 
STUDIJE O MUZIČKOJ UMETNOSTI/STUDIES ON MUSIC

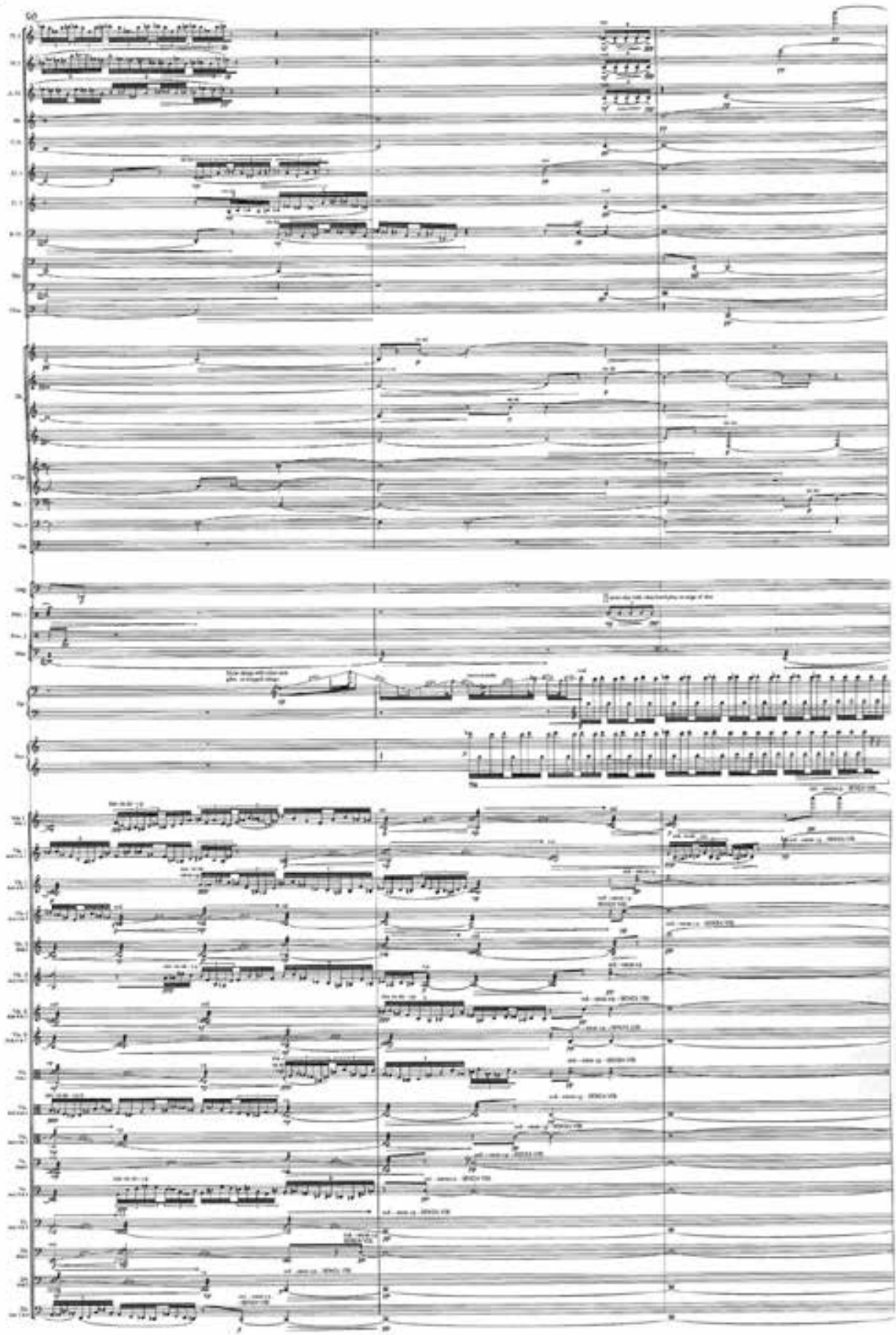

Example 4. Aeriality, bars 90-92 


\section{Entropy}

As mentioned above, an interesting aspect to investigate is the translation of a scientific concept, e.g. entropy, into the artistic field —in other words, how a scientific concept can be used in an analysis of a piece of music: what the correspondences are and what information about the piece it can shed light on. Of course, this approach, in music too, is not completely new.

The concept of entropy in physics originally comes from thermodynamics, the branch of physics that studies heat and energy. Entropy is related to the amount of „disorder" in a system. It is stated that entropy is a state variable of a system which measures the impossibility of producing work. ${ }^{12}$ In thermodynamics, work is the amount of energy transferred from a system to the surrounding environment. When part of the energy is not transmitted to the surrounding environment and is "lost" in the form of heat, entropy is produced..$^{13}$

Applied to music, entropy can be defined as the „temporal evolution“ of a musical structure. Entropy can be considered in one or more musical parameters. In general, physics studies systems and the processes that modify them; mathematics allows for the description of the transformations on the systems. In music, there are „initial states“ that can be themes, melodies or, more generally, groups of timbres and sounds. Within a musical composition, the initial musical material is transformed, and this transformation can be described through words, schemes, diagrams, approximate formulas, and mathematics. From physics to composition, it is possible to transfer not only sounds but also structures and processes. Therefore, in music, the continuous evolution of some initial materials implies an increase in entropy. It is possible to consider the „constant amount" of entropy in a given musical space. For example, a repetition of fragments without any change would have a constant level of entropy. As the volume of space increases, our knowledge decreases and entropy increases. Factors that determine the increase of entropy are the addition of instruments (sound hypertrophy), the addition/modification of timbres, variations of rhythm, and variations of dynamics. Not everything has to change at the same time: entropy can be considered with respect to one or more musical parameters. A high degree of entropy can also be associated with silence: in fact, silence (rest) is a condition of homogeneity. The two

12 In physics terminology, a force "produces work" when it can move an object, moving the "point of application of force" along the direction of the force itself. Work is equal to the variation of kinetic energy. 13 The concept of entropy is also used in other fields such as economics and social studies. In classical mechanics, entropy is expressed in terms of variation; however, entropy is also used in quantum mechanics, using an absolute definition through entanglement and a matrix that describes the evolution of the system. Moreover, in information theory, entropy measures our uncertainty about a random signal. Entropy is a measure of our lack of information. 
extremes - the extreme rhythmic complexity on the one hand and the total silence on the other - can therefore be seen as two points that come together, like the two ends of a segment that close and become a circle.

From the very first listening of Aeriality, it is possible to hear events that „introduce energy“ into the continuous sound flow. These events are responsible for the increase in entropy. The factors that produce such a type of phenomenon are many: notes plucked in $f$, increase/decrease from $p$ to $f$ (and vice versa), and repeated notes (from $f$ to $p$ with a diminuendo). The following example shows where increasing and decreasing entropy is placed within the 109 bars of the piece. It is important to underline that these results came out only listening to the piece. The numbers which are arranged progressively represent the bars in the score. Below them, the upward facing vertical arrows show the points where entropy increases (always suddenly). The diagonal arrows (upwards and downwards) indicate where entropy increases and decreases gradually. Of course, various analyses of this type may show small variations in the positioning of the arrows. This is because this type of analysis shows the saliences that emerge when listening. The different analyses of the saliences are never identical. It depends on many factors that are related to the music analyst's choices. The choice of parameters and the contextualization of the factors that manage entropy in a composition is completely contextual.

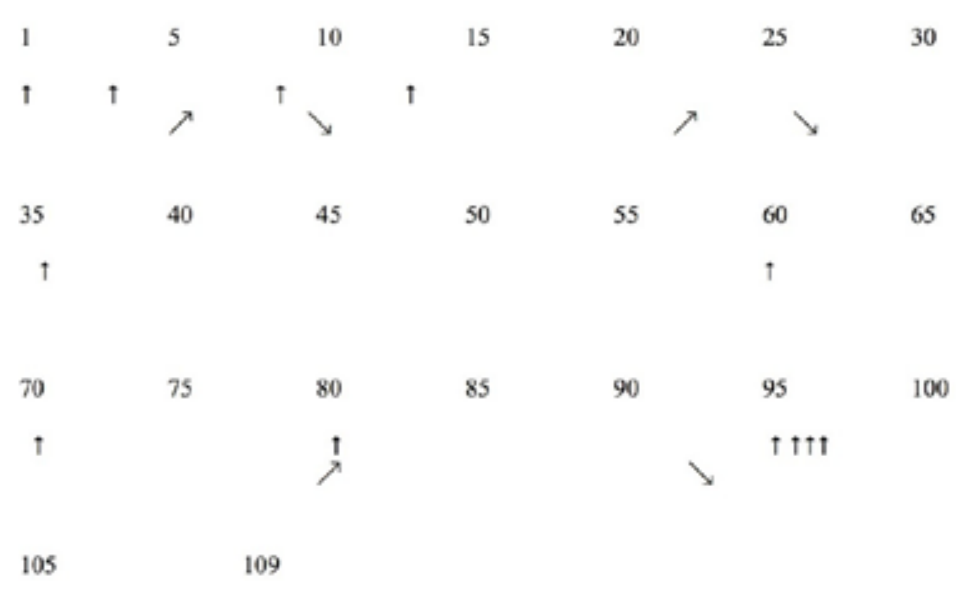

Example 5. Scheme of the variations of entropy (from a listening experience) 
From Ex. 5, it is possible to appreciate a great variation of entropy in section 1 (bars 1-19), much smaller and more gradual in section 2 (bars 20-52), more rarefied in the third and fourth sections (bars 53-72 and bars 72-91), and suddenly increased at the beginning of the fifth section (bars 92-109). In other words, entropy takes on different values in the various parts of the composition. It is possible to calculate its variation and also to calculate the variation between different sections of the composition. In order to examine the entropic trend of the piece in greater detail, it is useful to develop a more system to investigate the entropic gradient and the variation of entropy, not just between sections but even between measures. For the moment, only the value of entropy at a few given points in the composition will be calculated. This is to show how it is possible to measure it in a quantitative way.

\section{Calculation of the variation of entropy ${ }^{14}$}

In this paper only the rhythmic entropy will be measured. In other words, for practical reasons and to facilitate the whole process, the analysis will be limited to one parameter. The starting point will be the Fourier transform, which has already been applied to the analysis of rhythm in studies on mathematics and music. ${ }^{15}$ A new version extended to entropy will be considered. ${ }^{16}$

The mathematical formalism introduced by the Fourier transform concerns the homonymous series used to break down a signal ${ }^{17}$ (a sound signal or a complex sound) into simpler mathematical objects (such as, for example, a sum of sine and cosine multiplied by appropriate coefficients) and the homonymous transform. It appears to be the appropriate instrument for the purpose of this study because it allows moving from one area, such as that of the score, to another, such as that of mathematical and rhythmic schematization. ${ }^{18}$ Since this paragraph's only purpose is to introduce an analytical tool

14 For the elaboration of this paper, I am grateful to two scholars: Dr. Emmanuel Amiot (Universite de Perpignan), who developed the formulas used herein and who helped me with the calculation, and Dr. Maria Mannone (Università di Palermo) for assistance in the evolution of reasoning.

15 For further studies on Fourier transforms in music analysis, cf. Amiot and Sethares, "An algebra for periodic rhythms and scales"; Amiot, Music Through Fourier Space: Discrete Fourier Transform in Music Theory; Mannone, Segmentation des sériest emporelles pour l'orchestration automatique; Thul, Measuring the Complexity of Musical Rhythm; Yust, Review of Emmanuel Amiot, Music through Fourier Space: Discrete Fourier Transform in Music Theory.

$16 \mathrm{Cf}$. Amiot, Entropy of DFT.

17 From a formal point of view, Charles Fourier introduced the series in order to solve the heat equation in a metal plate. He published the initial results of his study in 1807 in "Mémoire sur la propagation de la chaleur dans les corps solides". In 1822, he published Théorie Analytique de la Chaleur, in which he explained the developments of his studies.

18 Usually, the discrete Fourier transform is referred to as DFT. 
for music, the concept of the Fourier transform will not be explained in its entirety here. ${ }^{19}$ Precise mathematical underpinnings and derivations of the relevant formulae have been omitted here as they are outside the scope of this essay.

Within mathematical music theory, the Fourier transform is applied to the study of pitch and rhythm. ${ }^{20}$ In this study, the discrete Fourier transform is applied to rhythm to measure its distribution and make numerical comparisons between different rhythms. ${ }^{21}$

To begin, it is necessary to study the rhythmic distribution and its periodicity in the fragment of the score that is considered. That is, some preliminary calculations are necessary. There is a starting set, which is a few bars of the score schematically represented as a string of numbers, leading to something else: either a real (or complex, see below) number or a scheme that gives quantitative information. It is important to keep in mind the relationship:

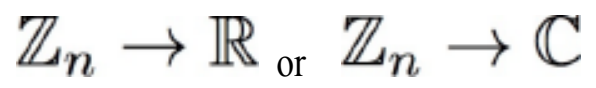

In this case, the starting set ${ }^{22}$ is indicated by „Z “, a cyclic group with integer values ${ }^{23}$ which - in the case of 12 tet tonal music - can be $Z_{12}$, and the finishing set consists of the real numbers (in the first mapping) or the complex numbers (in the second mapping). ${ }^{24}$ In the $Z_{n}$ script, $n$ indicates cyclicality. The main idea of Fourier transform is a map, i.e., a transformation. The logic of using these complex exponentials is to derive their periodicity. In the proposed analysis, discrete sets of parameters, such as notes or rhythms, will be considered. Also, the transform defined on „windows" will be considered. It moves to „cover" the entire fragment taken into examination. The usefulness of considering windows and not ,instant" values is well-suited to music, which is examined in sequences and not all in one moment. The map shown below starts with a set of notes (a chord), and the arrival yields a sum of complex exponentials that provide easily comparable numbers. ${ }^{25}$ The exponentials of the formula are multiplied by coefficients.

19 This is because this article is intended to be read and understood by musicians without requiring them to have a precise scientific background.

20 Cf. Amiot, Discrete Fourier Transform of Distributions.

21 The Fourier transforms have already been applied to musical analysis: it is the case of the rhythmic characterization of passages of the Spring Festival by means of the „flatness“ of the Fourier coefficients, but entropy and Fourier transforms had not yet been combined together in this scope. Cf. Mannone, Maria, op.cit.

22 The twelve notes of chromatic scale.

23 In mathematics, a group is a set on which operations are defined that combine two elements to give a third, which satisfy certain properties, including reversibility.

24 Complex numbers consist of a real part and an imaginary part, preceded by the imaginary unit „i“, the square root of -1 .

25 Cf. Amiot, Discrete Fourier Transform of Distributions. 


\section{(1)}

The DFT of $\{0,3,6,9\} \subset \mathbb{Z}_{12}$ is the map

$x \mapsto \sum_{k=0}^{3} e^{-2 i \pi 3 k x / 12}=1+(-i)^{x}+(-1)^{x}+i^{x}= \begin{cases}4 & \text { if } x \in\{0,4,8\} \\ 0 & \text { else }\end{cases}$

The resulting calculations provide information on the geometry of the starting set. Shannon's definition of entropy, used to quantify information in a system, is summarized by the following equation:

(2)

$$
H(X)=\sum_{k=1}^{n-1}-p_{k} \log p_{k}
$$

$\mathrm{H}$ is the symbol used to indicate entropy. The formula indicates a summation (in this case, a series of functions) with a parameter $k$ that varies from 1 to $n-1$.

Now it is possible to consider a version of entropy that contains the information provided by the Fourier transform, in particular, its coefficients. In this formula of entropy, developed specifically for musical analysis by the mathematical music theorist Emmanuel Amiot, $p_{k}$ is the normalized distribution of the Fourier coefficients:

$$
p_{k}=\frac{\left|a_{k}\right|^{2}}{\sum_{j=1}^{n-1}\left|a_{j}\right|^{2}}=\frac{\left|a_{k}\right|^{2}}{d(n-d)}
$$

fork $=1, \ldots, n-1$,

where $a_{k}$ is defined as:

(4)

$$
a_{k}(X)=\sum_{j=1}^{d} e^{-2 i \pi k x_{j} / r}
$$


In (4), the $X$ set has a number of elements. The square module indicates the magnitude of the Fourier coefficients, which provides information on their geometry. In this first musical application, the phase is neglected and subsets of $Z_{n}$ are all considered to be the same size. Since the first term of the series is the same for all sets of the same size, in the definition proposed by Amiot, the first terms are all equal to a constant and can be overlooked. In (3), the $d$ is used to carry out the normalization. The value of $d$ is given by the number of elements in the subset of $Z_{n}$. For example, if -in a measure with the total duration of a semibreve (i.e., 32 demisemiquavers) - a small group of four demisemiquavers is considered, the period is $n=32$ and $\mathrm{d}=4$.

In (3) and (4), $a$ is a coefficient with index $k$, which depends on the period $n$, the periodicity of the rhythm. $X$ is the starting set, which in our case is the given rhythmic sequence (a string of numbers). $X$ is a subset of $Z_{n}$. Parameter $k$ is a module that varies from 1 to $n-1: k$ therefore depends on the periodicity. For example, considering pitches rather than rhythms, in the case of the series of 12 notes, if one starts from $C(0)$ and arrives at the $C$ in the upper octave (12), it is possible to continue from scratch: therefore $12=0$ in modulo 12.

To show the way in which entropy is calculated according to this methodology, we will consider bars 18-20 (Ex. 1) of the score.

In particular, exclusively for reasons of practicality and simplification, the same bars will be taken into consideration in the violin II line, desk 4-5 (Ex. 6).

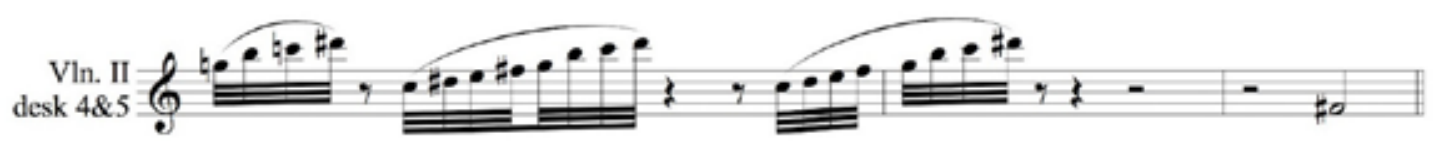

\section{Example 6. Aeriality, bars 18-20 -Violins II, desks $4 \& 5$}

This is a partial excerpt that will not provide an accurate entropy value (as it should be measured on all instruments). However, in this case, it is done exclusively to show the method of calculation.

The equation (2) will be applied to this fragment to find the variation of entropy. $X$ in the formula is the starting set, i.e., the rhythm we are considering (the string of numbers mentioned above). $k$ is an index that varies from 1 to 31 , i.e., from 1 to $n$-1, where $n=32$. In fact, 32 is the smallest subdivision that affects the bars examined (i.e., the demisemiquavers, i.e., 1/32). Ex. 8 shows the distribution of the rhythmic values in the circle with $n=32$ notes. In literature, ${ }^{26}$ ' $n$ ' indicates the period of the rhythm under 
examination. For simplicity, the duration of a single measure is indicated as a period herein order to have a tool to potentially apply to the entire composition. The value of $d$ is 16 for bar 18, 4 for bar 19, and 1 for bar 20 .

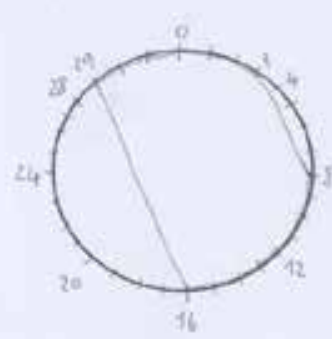

batt.18

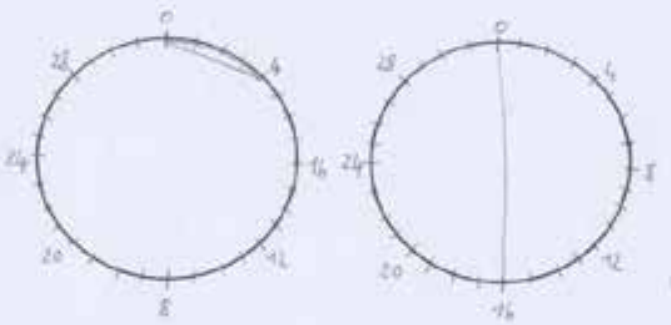

batt.19 batt.20

\section{Example 7. Distribution of the rhythmic values in the circle with $\mathbf{n}=\mathbf{3 2}$ notes}

First the value of $a_{k}$ in (4) will be calculated. Then, with this value and the constant $d$, it will be possible to find $p_{k}$. Finally, with $p_{k}, H$ can be found using the formula (2), which is the value of the entropy we are looking for. Repeating the operation for the three bars examined, the variation of entropy (or rather, the decrease of entropy) will emerge. Thus, the calculation will be:

entropy $[\{0,1,2,3,8,9,10,11,12,13,14,15,28,29,30,31\}, 32]$ entropy $[(\theta, 1,2,3), 32]$

entropy $[(16), 32]$

\section{Dut $=2.360609$}

\subsection{0}

\section{Ont $=3.433987$}

\section{Example 8. Calculation of entropy for bars 18-20 (Violins II, desks 4\&5)}

In the first line (Ex. 8) the values of the circle of bar 18 are reported, in the second line, those of bar 19, and in the third line, those of bar 20. The fact that the first value is lower than the third (and not vice versa) is not surprising: this is because the rhythm is less repetitive here. In this case, it is necessary to consider the inverse in such a way that the greater rhythmic density corresponds to a greater activity: this therefore corresponds to greater entropy. Because of the many steps and amount of time required, 
it is not efficient to study all the variations of entropy in the whole piece in this way. To calculate the values of entropy in every bar, it is useful to use a calculation program that does so quickly and with negligible margin of error (this will be one of the future developments).

The formula can therefore be applied to measure the entropy of certain musical passages; the comparison of entropy values gives the variation of entropy in a piece of music. In future studies, generalizing the method, it will be possible to define the entropic gradient at a specific point in the composition, or its variations if several points are considered. One of the future objectives is to draw the curve that will reveal the entropic dynamism in an entire composition.

\section{The concept of rhizome and its applications}

Another type of investigation of the score is one that considers the figure and concept of the rhizome (Ex. 10) and translates it into the musical field. From a morphological point of view, the rhizome is elongated and has various branches which develop horizontally under the ground. On occasion, they have a cylindrical shape and are arranged in a vertical position. The rhizome should not be confused with the stolon. On the contrary, it is a stem creeping on the ground and has the function of vegetative reproduction.

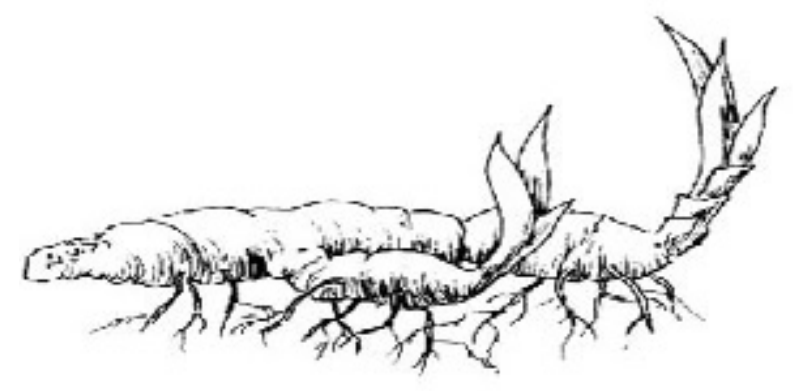

\section{Example 9. Figure of a rhizome}

The figure of the rhizome was used as a conceptual metaphor by the French philosopher Gilles Deleuze (1925-1995) and his colleague Félix Guattari (1930-1992). The two philosophers used it to explain a type of research that proceeds in multiples, that has no beginning or end, and that has no internal hierarchies. ${ }^{27}$ This vision is

27 They are not the only ones to use the rhizome as a metaphor. The psychoanalyst Carl Gustav Jung (1875-1961) quoted it in reference to the invisible nature of life. The French writer and poet Édouard 
explained in their book Thousand Plateaus: Capitalism and Schizophrenia (1987). Here the authors contrast the rhizomatic conception of thought with an arborescent conception typical of traditional philosophy which proceeds hierarchically and linearly in a vertical sense, following rigid binary or dualistic categories. The „rhizomatic thought", in contrast, can establish connections in any direction. Deleuze-Guattari's intention is to study these lines (i.e., the roots of the rhizome) and to study the way in which the elements of a broken assembly can form new assemblages.

In more schematic terms, it could be argued that Deleuze intends to oppose the tree with the rhizome. The tree schematizes the traditional paradigm of philosophical knowledge. According to his vision, he uses this vertical model to represent univocally and unidirectionally the sense of connection of the various philosophical concepts. The rhizome instead develops according to a horizontal — and therefore, less authoritarianparadigm. This latter model would be even more consistent with the idea of a nomadic philosophy and the theory of a diffusion of concepts and ideas „by contagion“ that has characterized many pages of his work.

\section{Rhizomatic archetypes}

This concept exhibited by Deleuze-Guattari can also be translated into the field of musical analysis. ${ }^{28}$ The rhizome is the whole piece within which one can find relations between elements, sections that recall the „new assemblages“ of which Campbell speaks ${ }^{29}$, that is, latent relations between parts that are sometimes distant from each other in the score. However, it is necessary to point out that what happens in nature is the vertical dimension. Deleuze argues about the intersecting and transforming rhizome (i.e., the development of the roots). In music, it is possible to connect these images to the melodic fragment. Of course, the listener will listen to these fragments over an amount of time, so in a row.

Before starting to analyze the score, it is necessary to clarify two key concepts for this type of analysis, in other words two terms used in this context: the center and the point of reference. ${ }^{30}$ The center is an element (a note or a fragment) that has a stabilizing effect, that is, a stable salience as its main and evident quality. The center emerges when listening and must be differentiated from the reference points, which are structures that

Glissant defines „unique root“ cultures as those that tend to self-preservation and „rhizome“ cultures as those born of a creolization.

28 For a larger explanation cf. Campbell, op.cit.

29 cf. Campbell, op.cit.

30 For an extensive explanation cf. Mastropasqua, L'evoluzione della tonalità. L'atonalità in Schönberg. These concepts can be found also in Favali, Federico, Il concept teatrale come architettura formale: la musica di Georges Aperghis. 
emerge from the analysis of the score. Reference points can be evident or latent-they are relationships that do not appear immediately on listening but can be discovered by analyzing the score. Of course, there is a possibility that a center will not be a reference point and vice versa. That is, the results do not have to match. Since this is essentially an analysis of the score, from now on the point of reference will be used. The discussion here does not claim to be exhaustive because its main purpose is to show an analytical approach that can then be developed and refined in the future. It is important to point out that the aspect of the center and point of reference is in reference to the harmony, and the concept of rhizome is in reference to a given melodic fragment. This distinction is very important because the concept of rhizome has non-hierarchic character. Certain rhizomatic archetypes will be presented here, but others may also be found.

At the very beginning of Aeriality, F\# constitutes the first point of reference. It is not restricted to a specific pitch-in fact, it will appear in various octaves and with various colors as it is played by various instruments. The reference point is the $\mathrm{F \#}$ as a note "in absolute value". Ex. 10 (bar 1) shows the beginning of the composition. Although one of the characteristics of the piece is the sound continuum, the beginning is „clear". Contrary to Ligeti's practice in these types of compositions, in this case the attack is very different from dal niente ${ }^{31}$ (although not all instruments attack together). ${ }^{32}$

From bar 3, the Fłappears ,out of focus“ and then again „in focus“. That is to say, the pitch is not very clearly defined: sometimes it is presented as F\#, sometimes as a quarter tone higher, and other times as three-quarters of a tone higher so as to describe a micro-cluster around the note, or perhaps a beginning of rhizomatic structure that starts from $\mathrm{F} \#$ and deviates from it, even if only by very little. Example 10 also shows the brass section at bar 3 where this process of „blurring“ takes place.

31 This can be related with certain pieces by G. Ligeti: lines and fast notes recall techniques used by him in several pieces (Melodien, Lux Aeterna, and Lontano, amongst others)

32 Cf. Ex. 11. 
STUDIJE O MUZIČKOJ UMETNOSTI/STUDIES ON MUSIC
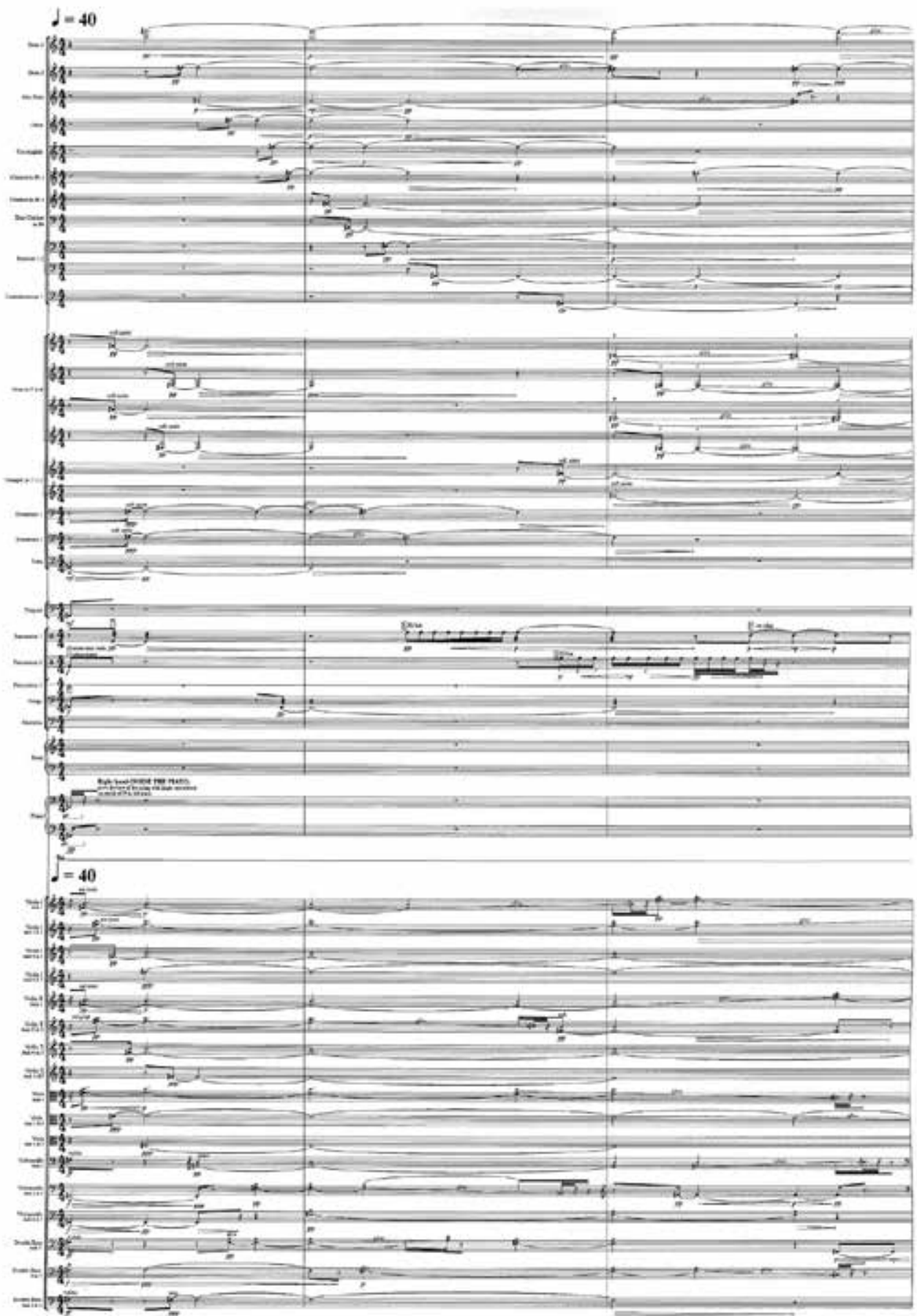

Example 10. Aeriality, bars 1-3 
This technique can be compared with the technique of focusing and "blurring" in the field of photography. Often, lines consisting of rapidly changing notes develop above held notes, which reveal points of reference (see below). They can be seen as the roots of the rhizome, i.e., those that grow downwards in the earth. On the other hand, the starting note of these lines at bar 4 is always F\#. Every time they reappear during the piece, they can be seen as a continuation, so they form a single large line starting from the $F \#$ : this is a clear representation of a rhizome. A little further on, in the same bar 4, two short lines start in opposite directions from C\#: one upwards (D-E) and one downwards (C-B): another rhizomatic archetype starting from a center other than F\#.
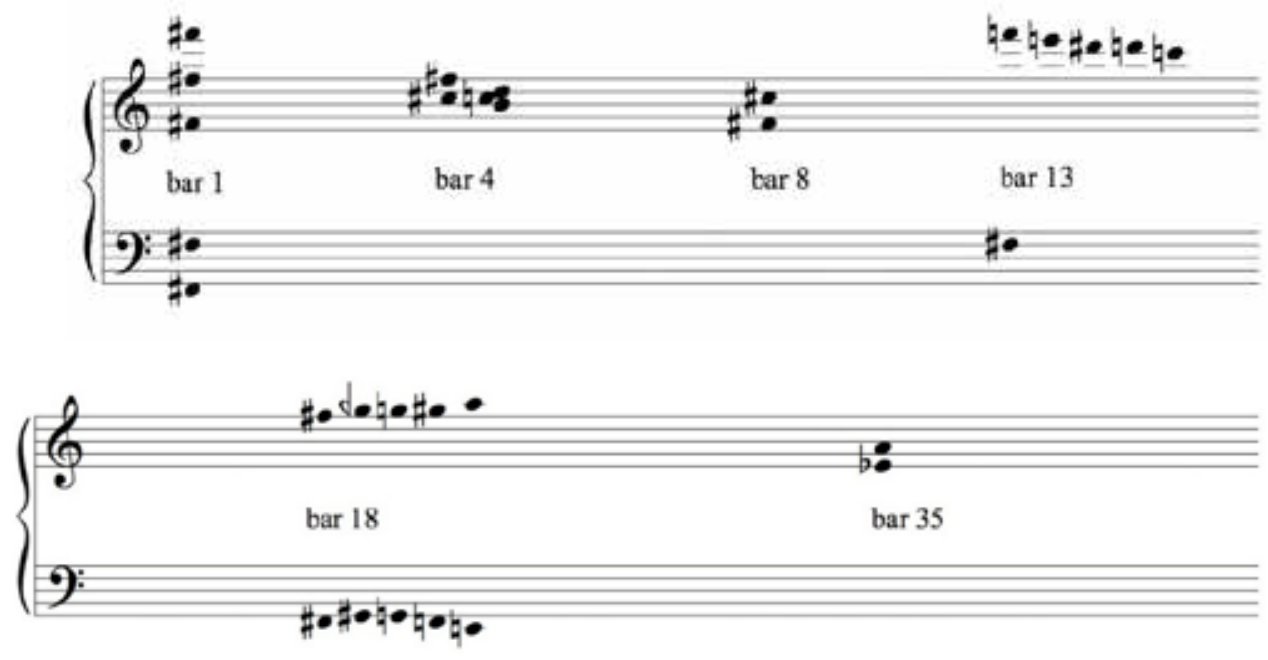

\section{Example 11. Scheme of rhizomatic archetype bars 1-53}

At bar 5, this interval widens further until it reaches the ends of A\#-E. The tritone reached above is the reference point, this time spanning three octaves. At bar 8, it expands further. Only the C\#remains above, which—given the structure of the texture - does not obscure the perception of the reference point, which remains clear until bar 11. From bar 13, another descending fragment reappears (F-E-D\#-D-C): the "blur" effect that recalls the rhizome. The "rhizomatic lines" reappear more consistently from bar 18. Here they dilate in the opposite direction until they reach E-A and last for several bars, up to bar 33 where-for the first time- $\mathrm{F} \#$ is lost as a reference point. 


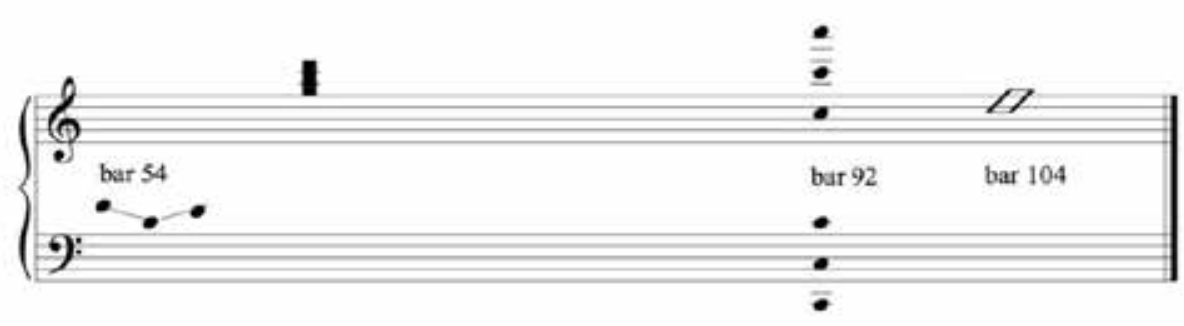

Example 12. Scheme of rhizomatic archetype bars 54-109

At bar 54, a section characterized by glissandos in the strings begins. The viola starts, and the rest of the string section follows. The effect creates a kind of magma. In a sense, we see the roots of the rhizome represented horizontally here. At the end of the section, clusters formed by notes a minor second apart reappear. Once again, they can be seen as the root of the rhizome that is going down. From bar 92, the note „C“ emerges with force as a new point of reference. It will remain so until bar 104. Here, clusters with indefinite pitches appear. That is, single notes are lost in indeterminate sounds.

\section{The new aesthetic}

What has been used in this essay can be defined as an analytical approach rather than a method, because it is not a standard procedure that leads to the achievement of a certain result, in this case the structure of a score. Here, it is a question of understanding which points of view bring the best result. From the viewpoint of an open work, we can see multiple points of view here. Given the different types of openings in a work, it is possible to assert that the aesthetic relationship between the work and the listener/ reader is open. This is the area in which this analytical approach is utilised. The French literary theorist Gerard Genette pointed out that a work never produces the same effect every time we hear or see it. Translated from conception into a temporal dimension, our relationship with the work changes with time: the work develops in time, and the user also changes in time. Their knowledge evolves, along with his ability to read. Consequently, time changes the relationship with the work itself. Our perception of a work of art also changes according to our level of culture and knowledge of the work itself. A self-referential analytical method essentially brings only a few information about the piece. An open approach instead brings more knowledge because the analysis is made from multiple directions, which is the main feature of the approach presented.

In the essay A New Kind of Aesthetics - The Mathematical Structure of the Aesthetic, the Japanese scholars Akihiro Kubota, Hirokazu Hori, Makoto Naruse, and Fuminori Akiba outline a plural path of aesthetic appreciation of the work of art with an oriented diagram (Ex. 14). 


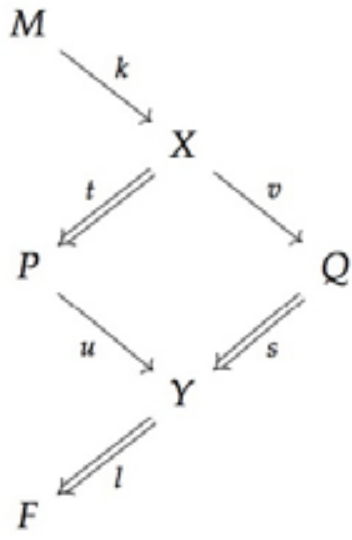

\section{Example 13. Oriented diagram of aesthetic appreciation}

In the diagram, the capital letters represent (in succession) $M$ : generative factor of the aesthetic object; $X$ : aesthetic concept; $P$ : observer; $Q$ : aesthetic object; $Y$ : aesthetic state; and $F$ : analytical results of the aesthetic state. The letters $k, t, v, u, s$, and $l$ represent morphologies, i.e.,-links between two mathematical structures with common abstract characters. They are not fixed, i.e.,, it is possible to describe the process in a different but equivalent way based on other morphologies.

It is evident that the aesthetic appreciation is given by the sum of several factors. They are all the analyses, following the different fields that we have tied to the piece. In fact, between the observer and the aesthetic object, from the point of view of analysis, there could be several arrows, each of which represents a different analytical approach. These arrows would be oriented by the listener to the aesthetic object. On the other hand, the work of art can be read in various forms, and the messages it transmits are multiple. The multidisciplinary approach therefore seems fully justified and worthy of development.

The technique of using new computational programs also opens areas of philosophical reflection to be developed. Is it possible to study entropy without technical tools? If the technical medium facilitates a task, can it be ignored? These are just a few of the questions on which to reflect. Of course, the combination of technology and music has been developing since at least the middle of the last century. Technical tools have changed our relationship with art and our way of listening to music. The relationship between composer and listener is therefore evolving and developing according to the characteristics of the age in which we live. 
One of the definitions of aesthetics says that the work of art is an artefact with an aesthetic function: as such, it is able to produce an aesthetic reaction in the user. The Argentine writer and critic Ricardo Piglia observed that ,a book is a transitional object, a surface where interpretations alternate" (Piglia, 2005). ${ }^{33}$ It is possible to apply that thought to a musical score. Then, a score becomes a surface where readings and interpretations follow one another from various points of view. Each of them produces an aesthetic reaction. For the analysis, we can therefore start from a non-musical field to arrive at the score or, vice versa, we can start from the score and relate it to other fields of knowledge. It depends not just on who analyzes it but also on who listens to it. Speaking of Jorge Luis Borges, Piglia pointed out: „,...]perhaps Borges' greatest teaching is the certainty that fiction depends not only on who builds it, but also on who reads it. Fiction becomes the theory of reading: not everything is fiction but everything can be read as fiction." (Piglia, 2005). If one sees the field of fiction as ,other" from the real one and relate it to forms of knowledge „other" than music, then we can understand that all scores can be read according to this formula. Thus it is possible to obtain a new theory of analysis. This is not surprising after the innovations made by Borges in the relationship between the work of art and its user. The final and definitive reaction is given by the union of all these facets that lead to a potential opening towards the infinite that every true work of art manages to embrace. Borges said that ,there is a concept that corrupts and confuses everyone else. I am not talking about Evil whose limited empire is ethics; I am talking about Infinity“" (Borges, 2019: 109). That is to say, the infinite also enters areas where the finite seems to dominate. It is the place of the work of art and it identifies with the infinite itself. On the other hand, who can understand and describe a work of art in its entirety? Only those who can see the Aleph.

\section{Aknowledgment}

Music examples from this paper are reproduced with kind permission of Hal Leonard Europe Limited. AERIALITY

Music by Anna Thorvaldsdottir

C Copyright 2011 Chester Music Limited.

All Rights Reserved. International Copyright Secured.

\section{REFERENCES:}

1. Amiot, Emmanuel \& Sethares William. 2011. "An algebra for periodic rhythms and scales", In: Journal of Mathematics and Music, 5(3), 149-169.

2. Amiot, Emmanuel. 2016. Music Through Fourier Space: Discrete Fourier Transform in Music Theory. Cham: Springer.

3. Amiot, Emmanuel. 2017. "The Discrete Fourier Transform of Distributions", In: Journal of Mathematics and Music, 11 (2-3), 76-100.

33 Piglia, El ultimo lector.

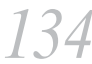


4. Amiot, Emmanuel. 2019. "Entropy of DFT", In: Journal of Mathematics and Music, (13), submitted.

5. Azzaroni, Loris. 1998. Canoneinfinito. Bologna: Clueb.

6. Bernard, Jonathan. 1986. "Space and Symmetry in Bartók", In: The Journal of Music Theory, 30(2), 185-201.

7. Borges, Jorge Luis. 2019. Altre inquisizioni. Milano: Feltrinelli.

8. Borges, Jorge Luis. 2010. L'Aleph. Milano: Feltrinelli.

9. Campbell, Edward. 2013. Music after Deleuze. London: Bloomsbury.

10. Caplin, William E., Hepokoski, James, Webster, James. 2010. Musical Form, Forms \& Formenlehre. Leuven: Leuven University Press.

11. Danto, Arthur. 1964. "The Artworld”, In: The Journal of Philosophy, 61(19), 571-584.

12. Deleuze, Gilles \& Guattari, Felix. 1987, Thousand Plateaus: Capitalism and Schizophrenia. Minneapolis: University of Minnesota Press

13. Deleuze, Gilles \& Guattari, Felix. 2002, L'anti-Edipo. Torino: Einaudi.

14. Eco, Umberto. 1976, Opera aperta. Milano: Bompiani.

15. Favali, Federico. 2017. Il concept teatrale come architettura formale: la musica di Georges Aperghis. Unpublished.

16. Gallope, Michael. 2008. "Is there a Deleuzian Musical work?", In: Perspectives of New Music46(2), 93-129.

17. Genette, Gerard. 1999.L'operadell'arte. Bologna: Clueb.

18. Kubota, Akihiro, Hori, Hirokazu, Naruse, Makoto and Akiba, Fuminori. 2017. "A New Kind of Aesthetics - The Mathematical Structure od the Aesthetic", u:Philosophies 3 (14), 1-10.

19. Mannone, Maria. 2013. Segmentation des series temporelles pour l'orchestration automatique, thesis submitted to the IRCAM in partial fulfilment of the requirements for the degree of master 2 Atiam, http://www.atiam.ircam.fr/Archives/Stages1213/MANNONE_Maria.pdf

20. Mannone, Maria \&Favali, Federico. 2019. "Categories, Musical Instruments, and Drawings: A Unification Dream.” In Montiel, Mariana, Gómez-Martin, Francisco \&Agustín-Aquino, Octavio (edts.), Mathematics and Computation in Music, Cham: Springer,59-72.

21. Margulis Hellmuth, Elizabeth\&Beatty, Andrew. 2008."Musical Style, Psychoaesthetics, and Prospects for Entropy as an Analytic Tool”, In: Computer Music Journal, 32(4), 64-78.

22. Mastropasqua, Mauro. 2005. L'evoluzione della tonalità. L'atonalità in Schönberg. Bologna: Clueb.

23. Piglia, Ricardo. 2005. El ultimo lector, Buenos Aires: Anagrama (e-book).

24. Stover, Chris. 2018. "Time, Territorialization, and Improvisational Space". In MTO, 23(1),https://mtosmt.org/issues/mto.17.23.1/mto.17.23.1.stover.html

25. Thul, Eric. 2008, Measuring the Complexity of Musical Rhythm, thesis of Master of Science, McGill University, Montreal, http://cgm.cs.mcgill.ca/ godfried/teaching/mir-readingassignments/Eric-Thul-Thesis.pdf

26. Valéry, Paul. 1922. "Le cimetièremarin". In Charmes: oupoèmes, Paris: Edition de la Nouvelle Revue Française.

27. Yust, Jason. 2017. "Review of Emmanuel Amiot, Music through Fourier Space: Discrete Fourier Transform in Music Theory". In MTO, 23(3), http://mtosmt.org/issues/mto.17.23.3/ mto.17.23.3.yust.html 


\section{Entropijska dinamika i rizomatični arhetipovi u delu „Aeriality“ Ane Torvaldsdotir}

Apstrakt: Islandska kompozitorka Anna Torvaldsdotir pripada novoj generaciji kompozitora koji su već prisutni na međunarodnoj sceni. Kako sama objašnjava, njene se kompozicije rađaju iz prirode: iz njenih dugih šetnji i promatranja dinamike, boja i zvukova same prirode. Orkestarsko delo Aeriality [Vazdušastost] iz 2011. godine predstavlja dobar primer ovakve poetike. U radu će se detaljno analizirati ova kompozicija i govoriće se o poetici autorke. Vodeći se sopstvenom idejom o „otvorenoj“ muzikologiji, koja je povezana s drugim oblicima znanja, a ne opisom partitura sledeći specifičnu analitičku metodu, biće istraženi pre svega mogući odnosi između kompozicionih struktura koje se mogu kvantitativno opisati. Poseban značaj biće dat konceptu entropije njegovim prevođenjem u muzičku terminologiju. Tačnije, biće prikazano kako premeštanje zvučnih masa u orkestru određuje povećanje ili smanjenje entropije. Zatim će se rad analizirati u skladu sa filozofijom i mišlju Žila Deleza, vodeći se glavnim pojmom njegove misli, rizomom. Konkretno, pokazaće se kako partitura sadrži arhetipove rizoma, te da ju je zapravo moguće čitati s ove tačke gledišta. Stoga je namera da se ostvari spona između dela ove kompozitorke i inovativnog pristupa.

Ključne reči: Aeriality, analiza, entropija, Torvaldsdotir, Delez. 